\title{
Editorial: Energy Justice in the Era of Green Transitions
}

\author{
Edgar Liu $^{1 *}$, Neil Simcock ${ }^{2}$ and Mari Martiskainen ${ }^{3}$ \\ ${ }^{1}$ Healthy Urban Environments Collaboratory, The Ingham Institute, Liverpool, NSW, Australia, ${ }^{2}$ School of Biological and \\ Environmental Sciences, Liverpool John Moores University, Liverpool, United Kingdom, ${ }^{3}$ University of Sussex Business \\ School, University of Sussex, Brighton, United Kingdom
}

Keywords: energy justice, energy transition, green energy, renewable energy, procedural justice, distributional justice, recognition justice

\section{Editorial on the Research Topic}

\section{Energy Justice in the Era of Green Transitions}

The need to rapidly decarbonize our energy systems to address the challenge of climate breakdown is now widely accepted. It is also increasingly recognized that processes of decarbonization ought to be undertaken in a manner that considers issues of justice and equity (Martiskainen et al., 2020; Calver et al., 2022; Knox et al., 2022). Over the past decade, the concept of "energy justice" has highlighted the multitude of ways that the operation of energy systems-and the ways that they change and evolve-can impact different places and sections of society in decidedly unequal and potentially unjust ways, but that there are also opportunities for energy systems to evolve to be more just and inclusive (McCauley et al., 2013; Sovacool et al., 2014; Sovacool and Dworkin, 2015; Jenkins et al., 2016; Bouzarovski et al., 2017).

This type of Research Topic is perhaps more pertinent than ever. The COVID-19 pandemic has highlighted, and arguably intensified, the centrality of energy services to our everyday lives and the functioning of societies (e.g., Carvalho et al., 2021; García et al., 2021; Rouleau and Gosselin, 2021).

\section{OPEN ACCESS}

Edited and reviewed by: Stefan Bouzarovski,

The University of Manchester, United Kingdom

*Correspondence:

Edgar Liu edgar.liu@unsw.edu.au

Specialty section

This article was submitted to Urban Energy End-Use,

a section of the journal

Frontiers in Sustainable Cities

Received: 18 January 2022

Accepted: 20 January 2022

Published: 14 February 2022

Citation:

Liu E, Simcock N and Martiskainen M

(2022) Editorial: Energy Justice in the

Era of Green Transitions.

Front. Sustain. Cities 4:857670.

doi: $10.3389 /$ frsc. 2022.857670
This Research Topic-Energy Justice in the Era of Green Transitions-seeks to contribute to ongoing research and debates regarding how current "green," or "climate neutral," energy transitions and policies might be causing, or avoiding, injustices, and the potential role such transitions might play in creating a more just society in the future.

In curating this Research Topic of 12 papers, we aimed to include a diverse range of contributions to enable a wide set of voices. While still largely Europe and North America focused, the Research Topic spans the Global North and South as well as the Eastern and Western hemispheres. This highlights the breadth and depth of research into energy justice across all corners of the globe but also, as the collection points out, shows that the experiences of energy injustice remain woefully common across many geographic and social contexts. The contributions come from a mix of established scholars as well as from emerging researchers publishing from their doctoral research, or their first publications. They also come from a range of disciplinary backgrounds, from architecture, environmental studies, geography, political sciences, psychology, and public and urban affairs to name a few. This diversity of disciplinary, geographic, and experiential backgrounds is reflected in the varied yet complementary approaches this Research Topic of papers took to addressing the broad topic.

The papers expose a range of energy (in)justice issues, covering the three established tenets of distributional, procedural, and recognition justice. Beginning with distributional justice, a key theme in several papers is the unequal ability of different sectors of society to engage with, and benefit from, sustainable energy innovations and policies. Focusing on a case study of Ontario in Canada, Wyse et al. highlight that, without policy and regulatory intervention, low-carbon innovations bring most benefit to private businesses and more privileged groups, whilst the more 
marginalized continue to be left behind. Reames shows that ethnic and racial disparities in domestic solar photovoltaic adoption in the USA cannot be explained solely by differences in resource potential. Rather, such disparities appear to be caused by deeply entrenched socio-economic and racial inequities experienced by communities of color. Through a case study of Mexico, Molar-Cruz et al. criticize "one-size-fits-all” energy policies and low-carbon subsidies, arguing that these often have regressive outcomes by most benefitting more affluent sectors of society.

Some of these inequitable outcomes may be long lasting, especially when concerning our built environment. Gower argues that shortcomings in housing regulation can embed unsustainable design, which in turn increases the energy vulnerability of residents over the long-term, ultimately entrenching socio-economic and tenure disparities long into the future. Cevheribucak discusses how, in Turkey, competing ideologies concerning energy transitions create unintended impacts on domestic energy poverty, and argues that any regressive outcomes from energy transition policies should be mitigated to prevent exacerbation of existing socio-economic inequalities. Finally, with a more conceptual take, Grossmann and Trubina liken the uneven experiences of energy poverty to violations of human dignity.

Several papers in this Research Topic also discuss concerns around procedural injustice, in terms of unfair or undemocratic policymaking processes. Reed et al. are highly critical of present climate change and energy transition policymaking in Canada. They show that the voices of Indigenous Peoples are not fully included in the design of two major climate change and netzero strategies, violating the core procedural justice principles of self-determination and informed consent. Si and Stephens similarly show that low-income households have limited political power and restricted ability to participate in the design of solar energy policies in Massachusetts in the USA, a situation they argue may lead to low-income households failing to benefit from solar technology. This echoes Bal et al.'s call for the importance of full engagement with social housing residents as part of lowcarbon building renovation, if a just and sustainable urban energy transition is to be achieved.

Finally, some papers highlight concerns around recognition justice. This is perhaps most evident in the piece by Feenstra et al., who argue that the experiences of vulnerable energy

\section{REFERENCES}

Bouzarovski, S., Tirado Herrero, S., Petrova, S., Frankowski, J., Matoušek, R., and Maltby, T. (2017). Multiple transformations: theorizing energy vulnerability as a socio-spatial phenomenon. Geografiska Annaler Ser. B Hum. Geogr. 99, 20-41. doi: 10.1080/04353684.2016.1276733

Calver, P., Mander, S., and Ghanem, D. (2022). Low carbon system innovation through an energy justice lens: exploring domestic heat pump adoption with direct load control in the United Kingdom. Energy Res. Soc. Sci. 83:102299. doi: 10.1016/j.erss.2021.102299

Carvalho, M., Bandeira, de. M. C. A., and de Souza, D. L. B. (2021). Effects of the COVID-19 pandemic on the Brazilian electricity consumption patterns. Int. J. Energy Res. 45, 3358-3364. doi: 10.1002/er.5877 consumers are often "invisible" in national policymaking. Similarly, Haarbosch et al. demonstrate a mismatch between the "narratives" and visions of energy transition policymakers versus those expressed by everyday citizens, with the perspectives of more marginalized citizens barely recognized within dominant policy narratives.

As well as highlighting current and potential injustices, however, what all the papers also make clear is that such inequities are not an inevitable consequence of green energy transitions, but rather can be avoided and/or mitigated by progressive policies and governance choices. Feenstra et al. argue that, if energy poverty mitigation is fully integrated into energy transitions policy, there is significant potential for both emissions reductions and greater social equity. In short, with political will, energy transitions can be a tool for greater energy justice. Equally, the paper by Pellegrini-Masini et al. indicates that citizens of more egalitarian societies show more favorable attitudes toward sustainable energy policies-greater justice, in turn, helps facilitate energy transitions.

As scholars, we must endeavor to delve deeper into the details, both qualitatively and quantitatively, to ensure that different sections of our societies-be they social, economic, cultural, locational, or otherwise-are able to enjoy the same opportunities to partake in and benefit from continuing green transitions.

\section{AUTHOR CONTRIBUTIONS}

EL wrote the first draft. NS and MM edited and revised subsequent drafts. All authors contributed to the article and approved the submitted version.

\section{FUNDING}

EL is funded by UNSW Sydney, University of Technology Sydney, Western Sydney University, NSW Government (South Eastern Sydney and South Western Sydney Local Health Districts) in Australia, and Australian Housing and Urban Research Institute Ltd (PRO41275). NS and MM receive funding from the UK Research and Innovation fund through the Centre for Research into Energy Demand Solutions (EP/R035288/1) and also NS receives funding from the Royal Geographic Society (with the Institute of British Geographers) (SRG 09/19).
García, S., Parejo, A., Personal, E., Guerrero, J. I., Biscarri, F., and León, C. (2021). A retrospective analysis of the impact of the COVID-19 restrictions on energy consumption at a disaggregated level. Appl. Energy 287:116547. doi: 10.1016/j.apenergy.2021. 116547

Jenkins, K., McCauley, D., Heffron, R., Stephan, H., and Rehner, R. (2016). Energy justice: a conceptual review. Energy Res. Soc. Sci. 11, 174-182. doi: 10.1016/j.erss.2015. 10.004

Knox, S., Hannon, M., Stewart, F., and Ford, R. (2022). The (in)justices of smart local energy systems: a systematic review, integrated framework, and future research agenda. Energy Res. Soc. Sci. 83:102333. doi: 10.1016/j.erss.2021. 102333 
Martiskainen, M., Sovacool, B. K., Lacey-Barnacle, M., Hopkins, D., Jenkins, K. E. H., Simcock, N., et al. (2020). New dimensions of vulnerability to fuel and transport poverty. Joule 5, 3-7. doi: 10.1016/j.joule.2020. 11.016

McCauley, D., Heffron, R., Stephan, H., and Jenkins, K. (2013). Advancing energy justice: the triumvirate of tenets. Int. Energy Law Rev. 3, 107-110. Available online at: http://hdl.handle.net/1893/18349 (accessed January 17, 2022).

Rouleau, J., and Gosselin, L. (2021). Impacts of the COVID-19 lockdown on energy consumption in a Canadian Social Housing Building. Appl. Energy. 287:116565. doi: 10.1016/j.apenergy.2021.11 6565

Sovacool, B. K., and Dworkin, M. H. (2015). Energy justice: conceptual insights and practical applications. Appl. Energy 142, 435-444. doi: 10.1016/j.apenergy.2015. 01.002

Sovacool, B. K., Sidortsov, R., Jones, B. R., Benjamin, K., Roman, V., and Benjamin, R. (2014). Energy Security, Equality, and Justice. London: Routledge. doi: $10.4324 / 9780203066348$
Conflict of Interest: The authors declare that the research was conducted in the absence of any commercial or financial relationships that could be construed as a potential conflict of interest.

Publisher's Note: All claims expressed in this article are solely those of the authors and do not necessarily represent those of their affiliated organizations, or those of the publisher, the editors and the reviewers. Any product that may be evaluated in this article, or claim that may be made by its manufacturer, is not guaranteed or endorsed by the publisher.

Copyright (c) 2022 Liu, Simcock and Martiskainen. This is an open-access article distributed under the terms of the Creative Commons Attribution License (CC BY).

The use, distribution or reproduction in other forums is permitted, provided the original author(s) and the copyright owner(s) are credited and that the original publication in this journal is cited, in accordance with accepted academic practice. No use, distribution or reproduction is permitted which does not comply with these terms. 